\title{
Neural Basis of Emotional Decision Making in Trait Anxiety
}

\author{
Pengfei Xu, ${ }^{1 *}$ Ruolei Gu, ${ }^{2 *}$ Lucas S. Broster, ${ }^{3}$ Runguo Wu ${ }^{4}$ Nicholas T. Van Dam, ${ }^{5,6,7}$ Yang Jiang, ${ }^{3}$ Jin Fan, ${ }^{6,7,8,9}$ \\ and Yue-jia Luo ${ }^{10}$ \\ ${ }^{1}$ State Key Laboratory of Cognitive Neuroscience and Learning, Beijing Normal University, Beijing 100875, China, ${ }^{2}$ Key Laboratory of Behavioral Science, \\ Institute of Psychology, Chinese Academy of Sciences, Beijing 100101, China, ${ }^{3}$ Department of Behavioral Science, University of Kentucky College of \\ Medicine, Lexington, Kentucky 40536, ${ }^{4}$ School of Social and Political Science, University of Edinburgh, Edinburgh EH8 9LD, United Kingdom, ${ }^{5}$ Department \\ of Psychiatry, New York University School of Medicine, New York, New York 10016, ${ }^{6}$ Department of Psychology, Queens College, City University of New \\ York, New York 10075, Department of Psychiatry, ${ }^{8}$ Fishberg Department of Neuroscience, and ${ }^{9}$ Friedman Brain Institute, Mount Sinai School of Medicine, \\ New York, New York 10029, and ${ }^{10}$ Institute of Affective and Social Neuroscience, Shenzhen University, Shenzhen 518060, China
}

Although trait anxiety has been associated with risk decision making, whether it is related to risk per se or to the feeling of the risk, as well as the underlying neurocognitive mechanisms, remains unclear. Using a decision-making task with a manipulation of frame (i.e., written description of options as a potential gain or loss) and functional magnetic resonance imaging, we investigated the neurocognitive relationship between trait anxiety and decision making. The classic framing effect was observed: participants chose the safe option when it was described as a potential gain, but they avoided the same option when it was described as a potential loss. Most importantly, trait anxiety was positively correlated with this behavioral bias. Trait anxiety was also positively correlated with amygdala-based "emotional" system activation and its coupling with the ventromedial prefrontal cortex (vmPFC) when decisions were consistent with the framing effect, but negatively correlated with the dorsal anterior cingulate cortex (dACC)-based "analytic" system activation and its connectivity to the vmPFC when decisions ran counter to the framing effect. Our findings suggest that trait anxiety is not associated with subjective risk preference but an evaluative bias of emotional information in decision making, underpinned by a hyperactive emotional system and a hypoactive analytic system in the brain.

\section{Introduction}

Anxiety can be viewed as an adaptive emotion that directs an individual to avoid potential threats (de Visser et al., 2010). Many studies suggest that risk-avoidance tendency may relate to survival from life-threatening situations (Clark, 1999; Maner and Schmidt, 2006; Nesse, 2006). However, some studies show that anxiety may lead to excessive risk-seeking in certain situations. For example, when risk-avoidant options are presented in an emotionally negative way, high anxious individuals are more likely to choose risky options (Chapman, 2006; Tang et al., 2012). Other studies show that anxiety and risk-avoidant behavior are not associated (Mitte, 2007; Gu et al., 2010a, b). Given that heightened anxiety is associated with attention, memory, and

Received March 22, 2013; revised 0ct. 6, 2013; accepted 0ct. 8, 2013.

Author contributions: P.X. and R.G. designed research; P.X., R.G., and R.W. performed research; P.X., Y.J., and Y.-j.L. contributed statistical analysis and data interpretation; P.X., R.W., and J.F. analyzed data; P.X., R.G., L.S.B., N.T.V.D., and J.F. wrote the paper.

This work was supported by the National Natural Science Foundation of China (31300847, 31300867, 30930031, and 91132704), the National Basic Research Program of China (973 Program, 2011 (B711000, 2014CB744600), United States National Institutes of Health (Grants 1R01TW007897, P50 DA005312, and T32 AG000242), the National Center for Research Resources (UL1RR033173), the National Center for Advancing Translational Sciences (UL1TR000117), and Scientific Foundation of Institute of Psychology, Chinese Academy of Sciences (Y2CQ013005). The content is solely the responsibility of the authors and does not necessarily represent the official views of the National Institutes of Health. We thank Xiaosi Gu for offering helpful comments.

The authors declare no competing financial interests.

*P.X. and R.G. contributed equally to this work.

Correspondence should be addressed to Dr. Yue-jia Luo, Institute of Affective and Social Neuroscience, Shenzhen University, Shenzhen 518060, China. E-mail: luoyj@bnu.edu.cn.

DOI:10.1523/JNEUROSCI.1253-13.2013

Copyright $\odot 2013$ the authors $\quad 0270-6474 / 13 / 3318641-13 \$ 15.00 / 0$ interpretative biases toward emotional stimuli (Mathews et al., 1989; Bar-Haim et al., 2007; Bishop, 2007), the mechanism for heightened risk aversion in anxiety seems to be, in part, the result of altered emotional information processing. Considering the prominent role of feelings in risk decision making (Loewenstein et al., 2001; Quartz, 2009), understanding the relationship between anxiety and risk-based decision making, by manipulating emotional context, is essential.

The "framing effect" refers to the phenomenon wherein the way information is presented (i.e., framed) significantly influences the upcoming decision (Tversky and Kahneman, 1981). People tend to choose the option framed as a potential gain but avoid the same option framed as a potential loss (Kühberger et al., 1999). The framing effect represents the impact of emotional information on human decision making (Druckman and McDermott, 2008; Fagley et al., 2010). That is, positive or negative information is integrated into the process of cognitive judgment and subsequently elicits an "approach" or "avoidance" tendency, respectively (Mittal and Ross, 1998; Deppe et al., 2007). Previous studies on the neural mechanisms underlying the framing effect have shown that the activation of an amygdala-based "emotional" neural system corresponds to decisions matching the frame and the activation of a dorsal anterior cingulate cortex (dACC)-based "analytic" neural system corresponds to decisions breaching the frame (De Martino et al., 2006; Roiser et al., 2009). Abnormal activity in both the amygdala (Deisseroth et al., 2011; Indovina et al., 2011) and the dACC (Nitschke et al., 2009; Straube et al., 2009) systems is associated with anxiety, indicating 
the potential influence of anxiety on frame-dependent decisionmaking (Kim et al., 2011; Hartley and Phelps, 2012).

In this study, we investigated the influence of trait anxiety on the neurocognitive mechanisms of risk decision making. We hypothesized that risk preference in trait anxiety is associated with processing emotional context, underpinned by corresponding neural circuits in decision making. We used Spielberger's Trait Anxiety Inventory (Spielberger et al., 1983) to measure trait anxiety. We adopted the framing effect task (De Martino et al., 2006) to manipulate contextual information in decision making while using functional magnetic resonance imaging (fMRI) to examine the related brain activity and connectivity. We predicted that trait anxiety would correlate to the framing effect behaviorally and that both emotional and analytic neural systems underlying the framing effect would be altered with trait anxiety magnitude.

\section{Materials and Methods}

Participants. Twenty-five healthy undergraduate students participated in the experiment. No participants had any history of neurological and psychiatric disorders or head injury. Written informed consent was obtained from each participant before MRI scanning. The experimental protocol was approved by the local Ethics Committee at Beijing Normal University.

Two participants were excluded from data analysis because of excessive head motion (absolute displacement relative to the reference scan exceeded a single voxel, i.e., $3 \mathrm{~mm}$ ), two because of poor task performance ( $>10 \%$ response omission), and one because of misunderstanding of task rules (as evidenced in debriefing). As a result, the final sample consisted of data from 20 participants (11 females; mean age $19.8 \pm 2.1$ years).

Before the experiment, participants completed the Chinese version (Shek, 1993) of the Spielberger's Trait Anxiety Inventory. Considering the strong overlap between anxiety and depression (Stavrakaki and Vargo, 1986; Clark and Watson, 1991), the Chinese version of the Zung self-rating depression scale (Zung et al., 1965; Shu, 1993; SDS) was also included to control for the potential influence of depression.

Experimental paradigm. The experiment was divided into three phases: an instruction phase, a formal task phase, and a post hoc debriefing phase (Roiser et al., 2009). In the instruction phase, participants acquired familiarity with the task via eight practice trials. In the formal task, participants were shown a fixation cross ( $2 \mathrm{~s}$ ) at the beginning of each trial, then a message screen $(2 \mathrm{~s}$ ) indicating a starting amount of points (e.g., "You receive 100 points," in Chinese; Fig. 1). Participants were informed that they would not retain all points but would have to select between a "sure" and a "gamble" option by pressing the left and right buttons on a button box. when a decision screen (4s) appeared. The positions of two options on the decision screen were counterbalanced across trials. Participants were informed before the experiment that task performance (i.e., total points) would contribute to their final payment. The relationship between point thresholds and corresponding participant payment was shown on a table, which indicated that the range of possible earning was 40-200 Chinese Yuan.

Within each trial, the expected values of the sure and gamble options were identical. The difference between conditions was the frame of the options, that is, the sure option was described as money retained in the gain (positive) frame condition (e.g., "keep 80 points" of 100 points) and was described as money lost in the loss (negative) frame condition (e.g., "lose 20 points" of 100 points). The gamble option was presented identically for both conditions and was represented as a pie chart depicting the probability of winning and losing in green and red, respectively (Fig. 1). No feedback was provided during the task. At the end of the task, total remaining/earned points was displayed to participants. At the end of the final phase, participants were debriefed and paid.

One exception to the balancing of the sure and gamble options occurred during "catch" trials. For half of these trials ("gamble-weighted"), the gamble option was preferable ( $95 \%$ winning probability via the gamble option vs guarantee of $50 \%$ of the initial amount); for the other half of
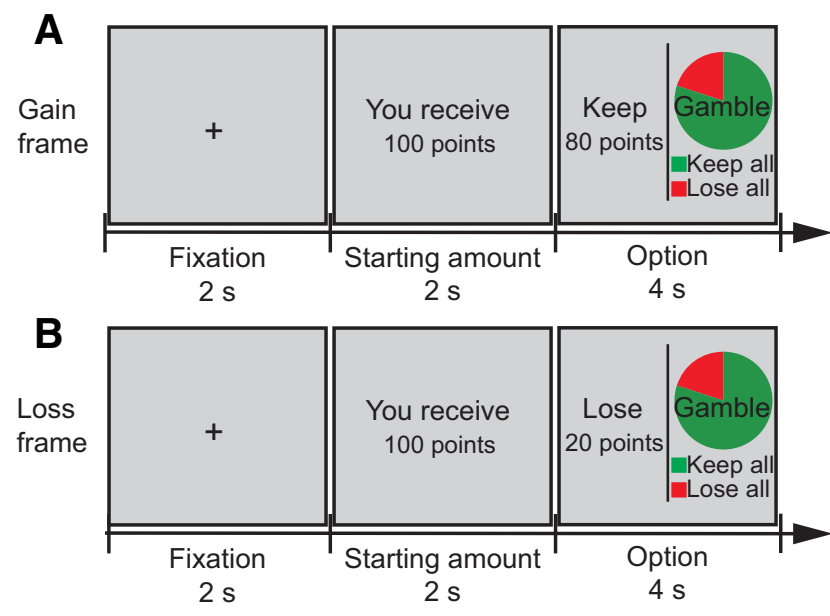

Figure 1. Schematic of the decision-making task. For each trial, after a 2 s fixation, a certain amount of money (e.g., "you receive 100 points" in Chinese in the figure) is presented for $2 \mathrm{~s}$. After that, a 4 s choice with a "sure" and a "gamble" option is displayed. The "sure" option states how much money will be retained from the initial amount ("keep 80 points") in the gain frame and how much money will be lost from the initial amount ("lose 80 points") in the loss frame. The "gamble" option states the probability of winning (in green) or losing (in red) the total amount of money for the trial, using a pie chart. The options were balanced across trials on the left and right side of the screen. $\boldsymbol{A}$, Gain frame. $\boldsymbol{B}$, Loss frame.

these trials ("sure-weighted"), the sure option was preferable ( $5 \%$ probability of winning by gambling vs guarantee of $50 \%$ of the initial amount). We included these trials to ensure that participants remained engaged throughout the task (De Martino et al., 2006). One-third of the trials in each session were "catch" trials (96 in total).

The formal task was divided into three identical sessions comprised of 96 trials ( 32 gain frame, 32 loss frame, and 32 catch trials; ordered pseudorandomly), consistent with the task design of De Martino et al. (2006). Each session lasted $12 \mathrm{~min} 48 \mathrm{~s}$. Stimulus display and behavioral data acquisition were conducted using E-Prime software (Version 1.1, Psychology Software Tools).

Behavioral data analysis. The framing effect was calculated as follows: $\left(\right.$ Gain $_{\text {sure }}+$ Loss $\left._{\text {gamble }}\right)-\left(\right.$ Gain $_{\text {gamble }}+$ Loss $\left._{\text {sure }}\right)$, that is, the difference between trials in which participants' decisions were affected by the frame (chose the sure option in the gain frame condition or chose the gamble option in the loss frame condition) and trials in which participants' decisions ran counter to the frame (chose the gamble option in the gain frame condition or chose the sure option in the loss frame condition), as in the study of De Martino et al. (2006). A one-sample $t$ test was performed, after removing the response omission trials, to test the framing effect. To explore the relationship between trait anxiety and the framing effect, a Pearson correlation was computed. A linear regression analysis was performed with trait anxiety and SDS scores as independent variables, and the framing effect as the dependent variable to control for the potential influence of depression.

Imaging data acquisition. MRI data were acquired using a Siemens MAGNETOM Trio 3T MR scanner powered with Total Imaging Matrix technique at the Imaging Center for Brain Research at Beijing Normal University. Both the fMRI and high resolution 3D structural brain data were obtained using a 12-channel phased-array head coil with the implementation of a parallel imaging scheme that generalized auto-calibrating partially parallel acquisitions (Griswold et al., 2002). The fMRI data were acquired with a gradient-echo echo-planer imaging sequence with the following parameters: repetition time $(\mathrm{TR})=2000 \mathrm{~ms}$, echo time $(\mathrm{TE})=$ $30 \mathrm{~ms}, 33$ transversal slices, slice thickness $3.5 \mathrm{~mm}$ with gap $0.7 \mathrm{~mm}$, flip angle $=90^{\circ}$, field of view $(\mathrm{FOV})=224 \mathrm{~mm} \times 224 \mathrm{~mm}$, data matrix $=$ $64 \times 64,387$ volumes scanned in $12.8 \mathrm{~min}$, and spatial coverage $(3.5+$ $0.7) \mathrm{mm} /$ slice $\times 33$ slices $\approx 139 \mathrm{~mm}$. In addition, the $3 \mathrm{D}$ structural brain images $\left(1 \mathrm{~mm}^{3}\right.$ isotropic) were also acquired for each participant using a T1-weighted 3D magnetization-prepared rapid gradient echo sequence with the following parameters: TR/TE $=1900 \mathrm{~ms} / 3.44 \mathrm{~ms}$, flip angle $=$ 
$9^{\circ}$, data matrix $=256 \times 256, \mathrm{FOV}=256 \mathrm{~mm} \times 256 \mathrm{~mm}, \mathrm{BW}=190$ $\mathrm{Hz} /$ pixel, 176 image volumes along the sagittal orientation, obtained in about $6 \mathrm{~min}$.

Imaging data analysis. Event-related analyses of the functional imaging data were conducted using statistical parametric mapping (SPM8; Wellcome Trust Centre for Neuroimaging). The functional images were first corrected for timing and then realigned to the first volume, coregistered to the T1 image, normalized to a standard template (Montreal Neurological Institute), and spatially smoothed with an $8 \mathrm{~mm}$ full-width-athalf-maximum Gaussian kernel.

To determine the brain activation underlying the framing effect, general linear modeling (GLM) (Friston et al., 1995) was conducted for the functional images from each participant by modeling the event-related blood oxygenation level-dependent (BOLD) signals and regressors. Regressors were created by convolving a train of $\delta$ functions representing the sequence of individual events with the default SPM basis function. In addition to the four levels of the framing effect (i.e., Gain ${ }_{\text {sure }}$, Loss $_{\text {gamble) }}$ Gain $_{\text {gamble, }}$ Loss sure ), event type-specific regressors were also included to exclude omission trial related BOLD responses. Six parameters generated during motion correction were entered as covariates. Low-frequency drifts in signal were removed using a high-pass filter with a cutoff at $128 \mathrm{~s}$. Serial correlation was estimated using an autoregressive AR(1) model. Linear contrasts of the parameter estimates were made to identify the main effects of frame and decision and the interaction effect between them (i.e., the framing effect), resulting in images of contrast estimate for these effects for each participant. The images from all participants were entered into one-sample $t$ tests for the second-level group analysis conducted with a random effects statistical model. The resultant voxelwise $Z$ statistic maps were thresholded at $p<0.05$, with a cluster-based correction for multiple comparisons using Gaussian random field theory (Worsley et al., 1992; Friston et al., 1994; Forman et al., 1995). The same cluster-level threshold was applied to all contrasts of the imaging analyses with the exception of the amygdala. Amygdala activation was thresholded with $p<0.05$ using a small-volume correction (Worsley et al., 1996), with an anatomical mask derived from the automated anatomical labeling atlas (Tzourio-Mazoyer et al., 2002).

Although the experiment constituted a $2 \times 2$ factorial design with the type of frame (Gain/Loss) as one factor and the behavioral decision (Sure/Gamble) of participants as the other, our primary aim was to examine the interaction between the frame type and the behavioral decision. The contrast of this interaction (i.e., $\left.\left(\mathrm{G}_{\text {sure }}+\mathrm{L}_{\text {gamble }}\right)-\left(\mathrm{G}_{\text {gamble }}+\mathrm{L}_{\text {sure }}\right)\right)$ represents the framing effect, that is, the behavioral tendency resulting from the frame. The framing effect implies that an individual decision is risk-avoidant under a gain frame and risk-seeking under a loss frame. The opposite contrast of this interaction (i.e., $\left.\left(\mathrm{G}_{\text {gamble }}+\mathrm{L}_{\text {sure }}\right)-\left(\mathrm{G}_{\text {sure }}+\mathrm{L}_{\text {gamble }}\right)\right)$ indicates that behavioral decisions of participants ran counter to the framing effect (De Martino et al., 2006).

To test our hypotheses about the amygdala-based emotional system and dACC-based analytic system, both regions of interest (ROIs) and wholebrain analyses were performed. All the ROIs were selected based on wholebrain activation elicited by the framing effect (Table 1 ). For the positive effect of frame, the left amygdala $(-24,-4,-10)$ was selected; for the negative effect of frame, the right dACC $(14,20,32)$, left anterior insular (AI) cortex $(-40,10,2)$, and right AI cortex $(36,18,10)$ were selected. All ROIs were extracted as 5-mm-radius spheres. Multiple linear regressions were performed with activation of ROIs as the dependent variable, and trait anxiety, behavioral framing effect, and the interaction between these two factors as independent variables. A whole-brain multiple regression analysis was performed to examine the effect of trait anxiety using a random-effects model, with individual trait anxiety and behavioral framing effect (i.e., ( $\mathrm{G}_{\text {sure }}+$ $\left.\left.\mathrm{L}_{\text {gamble }}\right)-\left(\mathrm{G}_{\text {gamble }}+\mathrm{L}_{\text {sure }}\right)\right)$ as predictors, and with brain activation of the framing effect as the dependent variable.

Considering that both amygdala and ventromedial prefrontal cortex (vmPFC) play important roles in anxiety (Bishop, 2007; Kim and Whalen, 2009) and decision making (Bechara et al., 2000; Hampton et al., 2007), psychophysiological interaction (PPI) analyses were conducted to further examine whether the modulation of the framing effect on the connectivity patterns of amygdala and vmPFC were associated with trait anxiety. For the PPI of the amygdala, the BOLD signal was extracted with the mask of the bilateral amygdala based on the automated anatomical labeling (AAL) template (Tzourio-Mazoyer et al., 2002), from the $T$ contrast of the framing effect in the first-level GLM analysis. For the PPI of the vmPFC, the BOLD signal was extracted from the reversed $T$ contrast of the framing effect in the first-level analysis, with the mask of the bilateral ventral ACC (as vmPFC) based on the AAL template. The second GLM was performed with PPI regressors of (1) the interaction of amygdala/vmPFC activity by the framing effect, (2) the main effect of amygdala/vmPFC activity, and (3) the main effect of the framing effect, corresponding to PPI.ppi, PPI.Y, and PPI.P in the design matrix.

Given the notable influence of head motion on brain functional connectivity (Mowinckel et al., 2012; Power et al., 2012; Satterthwaite et al., 2012; Van Dijk et al., 2012), correlations were computed between trait anxiety/ behavioral performance of framing effect, and both conventional rootmean-squared head motion and frame-wise displacement (a frame-byframe head movement) based on six motion parameters (Power et al., 2012). None of the correlations was significant $(p s>0.20$ for the correlations among trait anxiety and head motion measures; $p s>0.10$ for the correlations among behavioral performance of framing effect and head motion measures). The six head motion parameters were entered into the GLM of PPI as covariates to regress out the possible influence of head motion.

To explore whether the brain activity in the interaction between amygdala/vmPFC and the framing effect was correlated with trait anxiety, both ROI and whole-brain analyses were performed. All the ROIs were extracted as 5-mm-radius spheres based on the activation of PPIs. The activation of vmPFC $(8,34,4)$ was selected from the PPI results of amygdala. The activation of bilateral amygdala, $(-30,6,-20)$ for left and $(22,-6,-14))$ for right, were selected from the PPI results of vmPFC and then averaged. The activation of dACC $(6,26,42)$ was selected from the PPI results of vmPFC. Pearson correlations were calculated between these ROIs and trait anxiety. The whole-brain regression model was also conducted with the interaction of amygdala/vmPFC activity by the framing effect (PPI.ppi) as the dependent variable and trait anxiety as the independent variable.

\section{Results}

\section{Behavioral framing effect and its relationship with trait anxiety}

A one-sample $t$ test revealed that the framing effect was significantly larger than zero (mean $\pm \mathrm{SD}, 24.65 \pm 16.94, t_{(19)}=6.47$, $p<0.001$ ); that is, participants were more likely to make decisions in accordance with the frame $\left(\right.$ Gain $_{\text {sure }}=53.1 \%$, Loss $_{\text {gamble }}=$ $54.0 \%)$ rather than counter to the frame $\left(\mathrm{Gain}_{\text {gamble }}=45.5 \%\right.$, Loss $_{\text {sure }}=44.4 \%$; Fig. $2 A$ ). Regarding catch trials, participants chose the sure option on $86.8 \%$ of the sure-weighted trials and chose the gamble option on $93.5 \%$ of the gamble-weighted trials. These results indicated the subjects' continued engagement with the task throughout the experiment.

Trait anxiety scores ranged from 28 to 55 (39.9 \pm 6.9). Correlation analysis revealed a significant positive correlation between trait anxiety and the framing effect $(r=0.68, p=0.001$, two-tailed; Fig. 2B). However, trait anxiety was not correlated with risk-avoidance tendency in either the gain frame condition $(r=0.01, p=0.95)$ or the loss frame condition $(r=$ $-0.29, p=0.21)$.

To control for the potential influence of depression, the relationship between SDS scores (range, 25-51; $34.8 \pm 7.4$ ), anxiety, and the framing effect was examined. Correlation analysis indicated that there was no correlation between depression and the framing effect ( $r=0.13, p=0.59$, two-tailed). There was a significant correlation between trait anxiety and depression $(r=$ $0.53, p=0.02$ ). To examine the possible contributions of depression and anxiety individually, we used linear regression analysis with trait anxiety and depression scores as independent variables (entered method) and the framing effect as the dependent variable. The regression model was significant $\left(F_{(2,17)}=9.69, p<\right.$ 
Table 1. Brain activation of the framing effect and the reversed pattern of the framing effect during the decision-making task ${ }^{a}$

\begin{tabular}{|c|c|c|c|c|c|c|c|c|c|}
\hline Region & $\mathrm{L} / \mathrm{R}$ & $B A$ & $x$ & $y$ & $z$ & $t$ & $Z$ & $p$ & $k$ \\
\hline \multicolumn{10}{|l|}{ Framing effect } \\
\hline Cerebellum crus I & $\mathrm{L}$ & & -36 & -66 & -26 & 4.25 & 3.52 & $<0.001$ & $4983^{b}$ \\
\hline Calcarine cortex & $\mathrm{L}$ & 17 & -4 & -60 & 10 & 4.03 & 3.38 & & \\
\hline Cerebellum IV, V & $\mathrm{L}$ & & -10 & -40 & -6 & 3.52 & 3.05 & & \\
\hline Lingual gyrus & L & 17 & -4 & -76 & 6 & 3.48 & 3.03 & & \\
\hline Cerebellum crus II & $\mathrm{R}$ & & 24 & -88 & -30 & 3.37 & 2.95 & & \\
\hline Cerebellum VI & $\mathrm{R}$ & & 30 & -76 & -16 & 3.36 & 2.94 & & \\
\hline Cerebellum VI & $\mathrm{L}$ & & -6 & -70 & -12 & 3.30 & 2.90 & & \\
\hline Vermis & & & 0 & -68 & -4 & 3.09 & 2.74 & & \\
\hline Precuneus & $\mathrm{L}$ & 7 & -10 & -52 & 74 & 4.04 & 3.39 & 0.015 & 1163 \\
\hline Superior occipital gyrus & L & 19 & -18 & -86 & 40 & 3.52 & 3.05 & & \\
\hline Precuneus & $\mathrm{R}$ & 7 & 6 & -66 & 62 & 3.24 & 2.86 & & \\
\hline Superior occipital gyrus & $\mathrm{R}$ & 7 & 20 & -78 & 54 & 2.96 & 2.65 & & \\
\hline Cuneus & $\mathrm{L}$ & 19 & 0 & -84 & 40 & 2.57 & 2.35 & & \\
\hline Amygdalac & $\mathrm{L}$ & & -24 & -4 & -10 & 2.63 & 2.40 & 0.008 & 32 \\
\hline \multicolumn{10}{|l|}{ Reversed pattern of framing effect } \\
\hline Inferior frontal gyrus & L & 6 & -60 & 8 & 18 & 4.94 & 3.91 & $<0.001$ & 13,687 \\
\hline Supplementary motor area & L & 6 & -6 & 6 & 58 & 4.26 & 3.53 & & \\
\hline Precentral gyrus & $\mathrm{L}$ & 6 & -38 & -10 & 52 & 3.86 & 3.27 & & \\
\hline Middle temporal gyrus & $\mathrm{L}$ & 21 & -50 & -42 & 8 & 3.74 & 3.20 & & \\
\hline Cerebellum VI & L & & -22 & -50 & -28 & 3.49 & 3.03 & & \\
\hline Inferior parietal lobule & L & 40 & -28 & -42 & 46 & 3.47 & 3.02 & & \\
\hline Insula & $\mathrm{L}$ & 13 & -34 & -30 & 24 & 3.47 & 3.02 & & \\
\hline Fusiform & L & 37 & -40 & -58 & -10 & 3.42 & 2.98 & & \\
\hline Cerebellum IV, V & L & & -20 & -42 & -26 & 3.35 & 2.93 & & \\
\hline Middle occipital gyrus & $\mathrm{L}$ & 19 & -38 & -62 & 8 & 3.30 & 2.90 & & \\
\hline Inferior frontal gyrus & $\mathrm{L}$ & 44 & -40 & 6 & 22 & 3.18 & 2.81 & & \\
\hline Paracentral gyrus & $\mathrm{L}$ & 4 & -6 & -30 & 68 & 3.14 & 2.78 & & \\
\hline Precuneus & $\mathrm{L}$ & 7 & -14 & -48 & 54 & 3.12 & 2.77 & & \\
\hline Middle frontal gyrus & $\mathrm{L}$ & 46 & -28 & 26 & 34 & 3.09 & 2.75 & & \\
\hline Superior parietal lobule & $\mathrm{L}$ & 7 & -28 & -48 & 52 & 3.03 & 2.70 & & \\
\hline Precentral gyrus & $\mathrm{L}$ & 6 & -46 & -6 & 42 & 3.02 & 2.69 & & \\
\hline Inferior frontal gyrus & $\mathrm{L}$ & 45 & -38 & 22 & 10 & 2.99 & 2.67 & & \\
\hline Insula & L & & -40 & 10 & 2 & 2.75 & 2.49 & & \\
\hline Precentral gyrus & $\mathrm{R}$ & 6 & 50 & 2 & 24 & 4.10 & 3.43 & $<0.001$ & 7754 \\
\hline Anterior cingulate gyrus (dorsal) & $\mathrm{R}$ & 32 & 14 & 20 & 32 & 3.73 & 3.19 & & \\
\hline Precentral & $\mathrm{R}$ & 6 & 40 & -10 & 46 & 3.22 & 2.84 & & \\
\hline Rolandic operculum & $\mathrm{R}$ & 6 & 54 & 6 & 14 & 3.20 & 2.83 & & \\
\hline Putamen & $\mathrm{R}$ & & 20 & 10 & 6 & 3.18 & 2.81 & & \\
\hline Postcentral gyrus & $\mathrm{R}$ & 3 & 36 & -24 & 48 & 3.06 & 2.73 & & \\
\hline Precentral & $\mathrm{R}$ & 6 & 44 & -6 & 54 & 3.06 & 2.72 & & \\
\hline Middle frontal gyrus & $\mathrm{R}$ & 10 & 24 & 32 & 30 & 2.93 & 2.63 & & \\
\hline Inferior frontal gyrus & $\mathrm{R}$ & 45 & 50 & 20 & 20 & 2.93 & 2.62 & & \\
\hline Insula & $\mathrm{R}$ & & 36 & 18 & 10 & 2.75 & 2.49 & & \\
\hline Caudate & $\mathrm{R}$ & & 16 & 16 & 12 & 2.73 & 2.48 & & \\
\hline Postcentral gyrus & $\mathrm{R}$ & 3 & 56 & -18 & 38 & 2.68 & 2.44 & & \\
\hline Inferior temporal gyrus & $\mathrm{R}$ & 37 & 42 & -48 & -12 & 3.67 & 3.15 & 0.001 & 2454 \\
\hline Middle temporal gyrus & $\mathrm{R}$ & 37 & 46 & -52 & -4 & 3.60 & 3.10 & & \\
\hline Cerebellum VIII & $\mathrm{R}$ & & 12 & -64 & -32 & 3.26 & 2.87 & & \\
\hline Cerebellum IV, V & $\mathrm{R}$ & & 24 & -40 & -26 & 3.05 & 2.72 & & \\
\hline Middle temporal gyrus & $\mathrm{R}$ & 21 & 52 & -54 & 10 & 2.73 & 2.47 & & \\
\hline Cerebellum VI & $\mathrm{R}$ & & 26 & -52 & -28 & 2.60 & 2.37 & & \\
\hline Fusiform & $\mathrm{R}$ & 37 & 30 & -38 & -14 & 2.60 & 2.37 & & \\
\hline
\end{tabular}

${ }^{a} \mathrm{~L}$, Left; $\mathrm{R}$, right; $\mathrm{BA}, \mathrm{Brodmann}$ 's area. Height threshold: $t=1.73, p<0.05$, extent threshold: $k=710$.

${ }^{b}$ For each cluster, the cluster size was reported in the line of the local maxima. The large cluster size in the current study resulted from a unified cluster-based correction for multiple comparisons with $p=0.05$ as the threshold to be consistent across all the data analyses.

'For the amygdala, a small-volume correction (Worsley et al., 1996) was applied, with an anatomical mask derived from the AAL atlas (Tzourio-Mazoyer et al., 2002) and with a voxel-level threshold $p_{\text {uncorrected }}<0.05$ and a search volume of $2200 \mathrm{~mm}^{3}$ (275 voxels). The same correction for the activation of amygdala was also used for Tables 2, 5, and 6.

$\left.0.01, R^{2}=0.50\right)$. Whereas trait anxiety was a significant predictor of the framing effect $(\beta=0.85, p<0.01)$, depression was not $(\beta=-0.32, p=0.12)$. These results suggest that the depression does not represent a confounding covariate in the relationship between anxiety and the framing effect. Thus, SDS was excluded from subsequent analyses.
Brain activation underlying the framing effect and its relationship with trait anxiety

Using GLM, the contrast of the framing effect, $\left(\mathrm{G}_{\text {sure }}+\mathrm{L}_{\text {gamble }}\right)-$ $\left(\mathrm{G}_{\text {gamble }}+\mathrm{L}_{\text {sure }}\right)$, revealed significant activation in the left amygdala (with the small-volume correction) (Fig. 3A; Table 1). For the reversed pattern of the framing effect, $\left(\mathrm{G}_{\text {gamble }}+\mathrm{L}_{\text {sure }}\right)-$ 
A

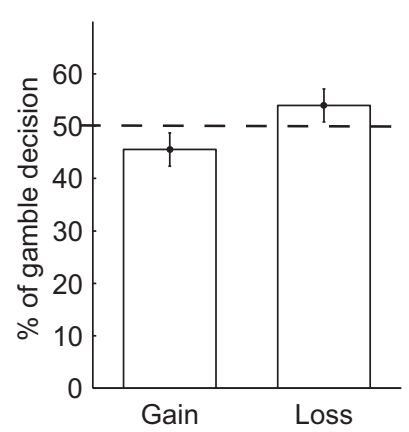

B

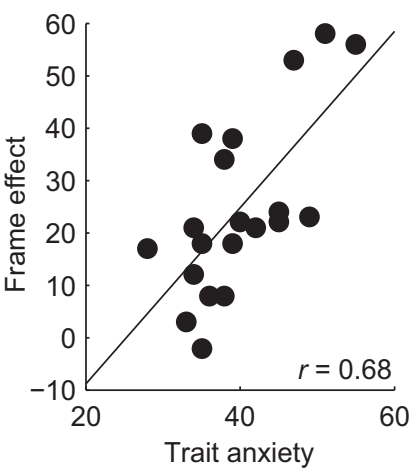

Figure 2. Behavioral framing effect and trait anxiety. $\boldsymbol{A}$, Percentage of "gamble" decisions made by participants in the gain frame condition and the loss frame condition. $\boldsymbol{B}$, A scatter plot of the correlation between trait anxiety (measured by Spielberger's Trait Anxiety Inventory scores) and behavioral framing effect (i.e., $\left.\left(\mathrm{G}_{\text {sure }}+\mathrm{L}_{\text {gamble }}\right)-\left(\mathrm{G}_{\text {gamble }}+\mathrm{L}_{\text {sure }}\right)\right)$.

correlated with activation in the amygdala. Neither the behavioral framing effect $(\beta=-0.05, p=0.33)$ nor the interaction between anxiety and the framing effect $(\beta=-0.01 ; p=0.13)$ was a significant predictor. For the right dACC, the regression model was significant $\left(F_{(3,16)}=5.24, p=0.01, R^{2}=0.50\right)$. In this model, anxiety $(\beta=-0.30, p<0.01)$ and the interaction between anxiety and the framing effect were both significant predictors $(\beta=0.01, p<0.01)$. These findings indicate that activation of $\mathrm{dACC}$ was negatively correlated with anxiety but positively correlated with the interaction between anxiety and the framing effect (Fig. $3 E$ ). The behavioral framing effect was not a significant predictor in this model $(\beta=0.02$, $p=0.69)$. For the left AI, the overall regression model was not significant $\left(F_{(3,16)}=1.01, p=0.42, R^{2}=0.16\right)$. For the right $\mathrm{AI}$, the regression model was again not significant $\left(F_{(3,16)}=0.73, p=0.55\right.$, $R^{2}=0.12$ ).

Using a multiple regression model, the contrast of the framing effect revealed a significant positive correlation between anxiety and left amygdala activation (Fig. $3 C$; Table 2) and a significant negative correlation between anxiety and activation in the bilateral dorsal lateral prefrontal cortex (dlPFC), bilateral dACC, and bilateral AI cortex (Fig. 3F; Table 2).
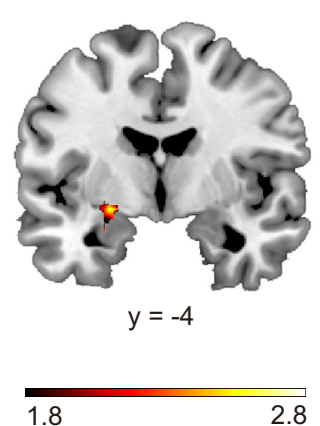

D

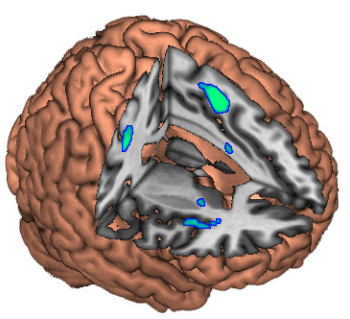

$-1.8$
B

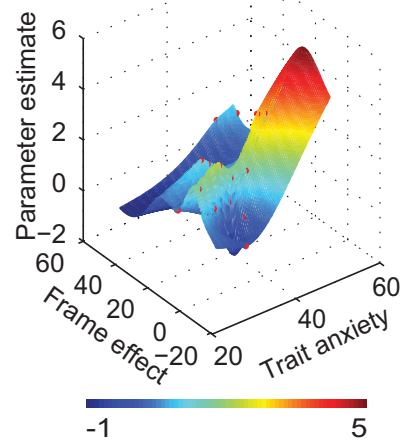

E

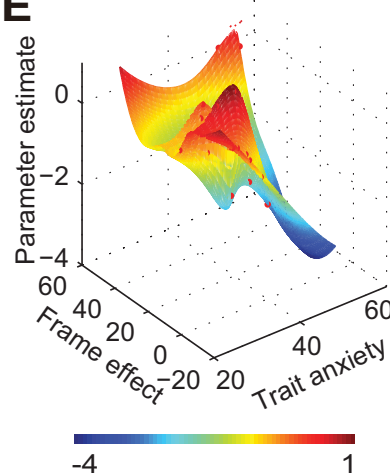

C

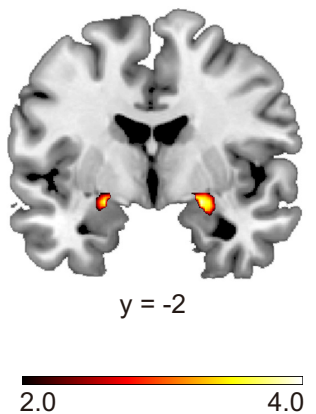

$\mathbf{F}$

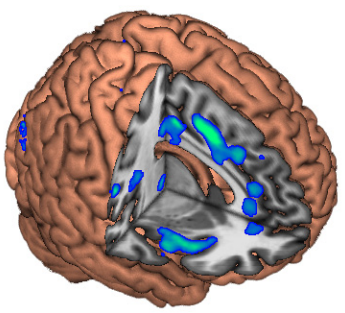

$-2.0$

\section{Brain connectivity underlying the} framing effect and its relationship with trait anxiety

With the framing effect as the psychological context and the BOLD signal of the amygdala as the physiological signal, PPI analysis showed that the bilateral amygdala was positively coupled with the vmPFC, postcentral gyrus, and supplemental motor area (Fig. 4A; Table 3). ROI analysis showed that the functional connectivity between amygdala and vmPFC was significantly positively correlated with trait anxiety $(r=0.61, p<0.01$; Fig. $4 B)$. The whole-brain regression analysis showed that anxiety was positively correlated with the modulation of the framing effect on the connectivity among the amygdala and vmPFC, bilateral AI, bilateral posterior cingulate cortex/precuneus, and bilateral dlPFC (Fig. 4C; Table 4). In other words, an increase in anxiety was related to an in increase functional connectivity between amygdala and vmPFC underlying the framing effect.

With the framing effect as the psychological context and the BOLD signal of the vmPFC as the physiological signal, the PPI analysis showed that the vmPFC was positively coupled with bilateral amygdala (Fig. 5A; Table 5) but negatively coupled

$\left(\mathrm{G}_{\text {sure }}+\mathrm{L}_{\text {gamble }}\right)$, we found significant activation in the right dACC and bilateral AI cortex (Zheng et al., 2010) (Fig. 3D; Table 1).

Considering the amygdala ROI as the dependent variable, the regression model of trait anxiety and behavioral framing effect (as independent variables) was not significant overall $\left(F_{(3,16)}=2.41\right.$, $p=0.11, R^{2}=0.31$ ), although anxiety was a significant predictor $(\beta=0.35, p=0.02$; Fig. $3 B)$, indicating that anxiety was positively with right ACC, bilateral AI, bilateral dlPFC, and bilateral intraparietal sulcus (Fig. 5D; Table 5). ROI analysis showed that the functional connectivity between vmPFC and amygdala was significantly positively correlated with trait anxiety $(r=0.54, p=$ 0.02 ; Fig. $5 B$ ). However, the functional connectivity between vmPFC and dACC was not significantly correlated with trait anxiety $(r=-0.33, p=0.16$; Fig. $5 E)$. The whole-brain regression analysis showed that anxiety was positively correlated with the 
Table 2. Positive and negative correlations between trait anxiety level and brain activations associated with the frame effect ${ }^{a}$

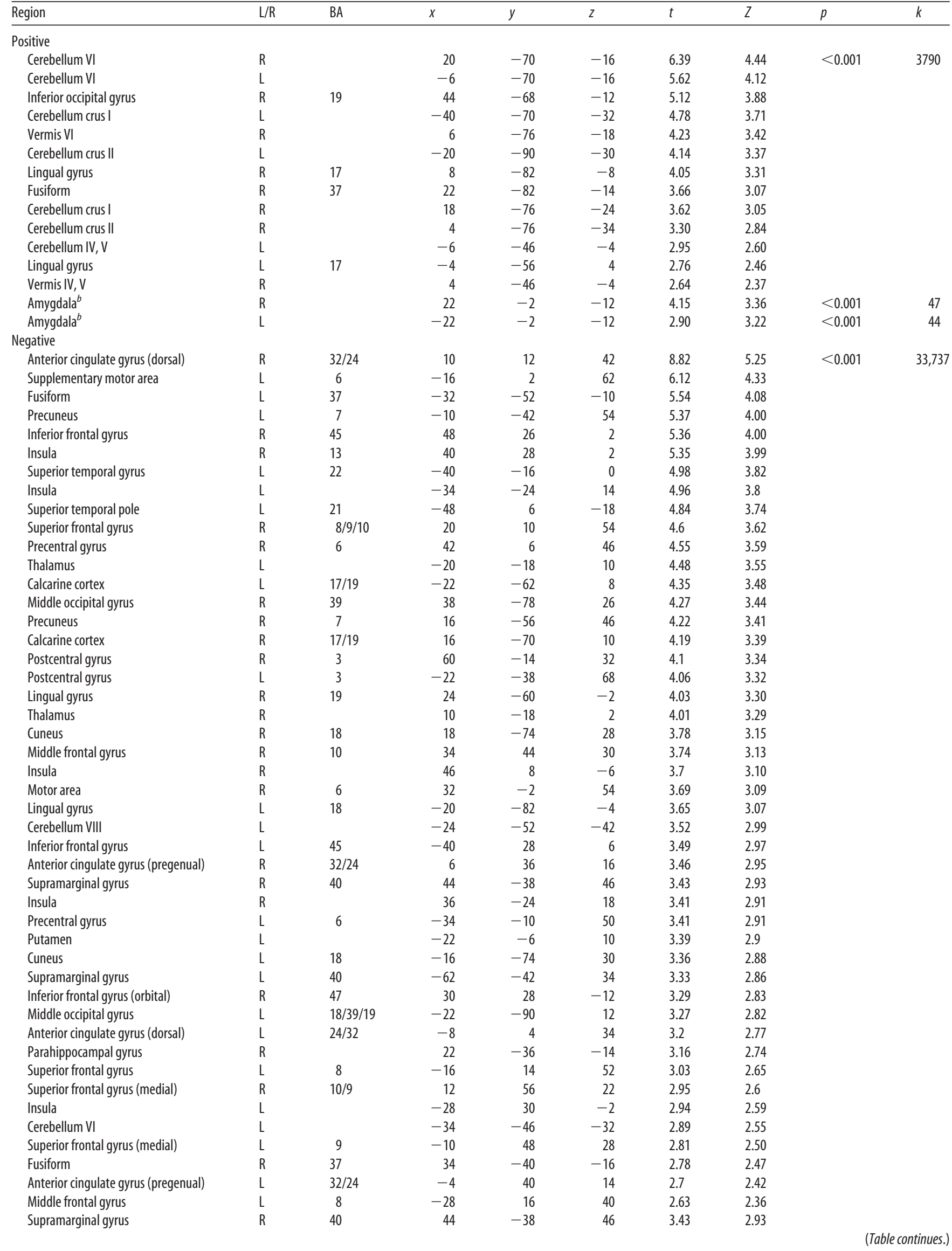


Table 2. Continued

\begin{tabular}{|c|c|c|c|c|c|c|c|c|c|}
\hline Region & $\mathrm{L} / \mathrm{R}$ & $B A$ & $x$ & $y$ & $z$ & $t$ & $Z$ & $p$ & $k$ \\
\hline Thalamus & L & & -20 & -18 & 10 & 4.48 & 3.55 & & \\
\hline Thalamus & $\mathrm{R}$ & & 10 & -18 & 2 & 4.01 & 3.29 & & \\
\hline Cerebellum IV, V & $\mathrm{L}$ & & -20 & -38 & -24 & 3.99 & 3.27 & $<0.05$ & 1171 \\
\hline Cerebellum VI & $\mathrm{R}$ & & 32 & -46 & -34 & 3.48 & 2.96 & & \\
\hline Cerebellum IX & $\mathrm{R}$ & & 18 & -52 & -44 & 3.47 & 2.95 & & \\
\hline Cerebellum VIII & $\mathrm{L}$ & & -8 & -56 & -38 & 2.83 & 2.51 & & \\
\hline
\end{tabular}

${ }^{a} \mathrm{~L}, \mathrm{Left} ; \mathrm{R}$, right; $\mathrm{BA}$, Brodmann's area. Height threshold: $t=1.75, p<0.05$, extent threshold: $k=670$ voxels.

${ }^{b}$ For the amygdala, a small-volume correction (Worsley et al., 1996) was applied, with an anatomical mask derived from the AAL atlas (Tzourio-Mazoyer et al., 2002) and with a voxel-level threshold $p_{\text {uncorrected }}<0.05$ and a search volume of $2200 \mathrm{~mm}^{3}$ (275 voxels).

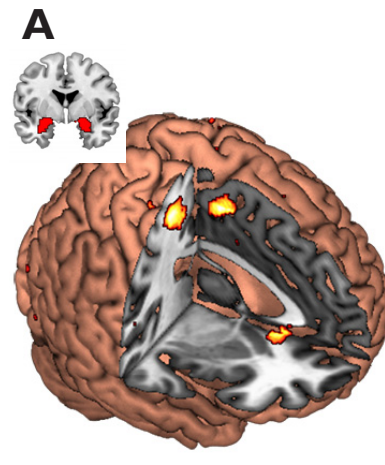

2.0
B

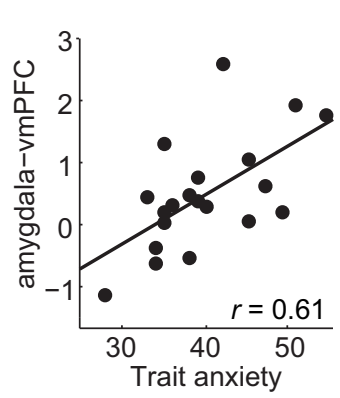

C

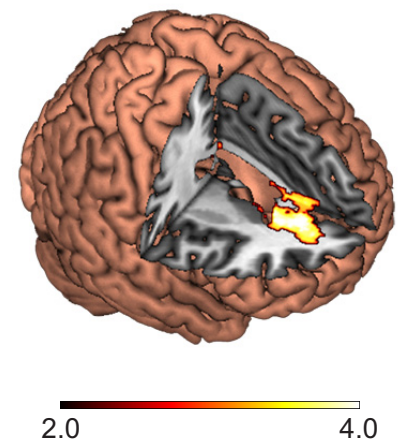

Figure 4. Functional connectivity of amygdala under the framing effect in trait anxiety. $\boldsymbol{A}$, Activation of amygdala was positively coupled with vmPFC under the framing effect. $\boldsymbol{B}$, The amygdala-vmPFC connectivity under framing effect was positively correlated with trait anxiety $(p<0.01$; ROI analysis based on $\boldsymbol{A})$. C, Positive correlations between amygdala-based circuits and trait anxiety (whole-brain analysis).

modulation of the framing effect on the connectivity between the vmPFC and the bilateral amygdala (Fig. 5C; Table 6). Anxiety was negatively correlated with the modulation of the framing effect on connectivity between the vmPFC and the bilateral dACC (Fig. $5 F$; Table 6). In other words, whereas increasing anxiety was related to a stronger functional connectivity between vmPFC and amygdala under the framing effect, increasing anxiety was related to weaker neural coupling of vmPFC and dACC.

\section{Discussion}

The present results showed that risk preference in trait anxiety was related to task-based framing of risky options. Our findings suggest that anxiety affects decision making by modulating the processing of contextual emotional information (i.e., information that has any emotional value) (e.g., Loewenstein et al., 2001), rather than by directly strengthening a risk-avoidance tendency. If this supposition was false, high levels of anxiety would have consistently led to choosing the low-risk option (sure option), regardless of frame condition. The idea that anxiety influences processing of emotional context rather than risk-aversion is supported by a recent study, which showed that individuals with heightened social anxiety exhibited decreased risk aversion compared with less anxious controls in a socio-emotional decisionmaking task (Tang et al., 2012). One possible explanation for these findings is that high-anxious people are prone be to probability-neglect (Loewenstein et al., 2001; Slovic et al., 2005) (insensitive to information about probabilities). Anxious individuals use external emotional messages rather than probabilistic information to evaluate the expected utility of each option (Quartz, 2009), indicating a stronger tendency to rely on the "affect heuristic" when making decisions (Finucane et al., 2000; Slovic et al., 2004).

We found that the framing effect, which is at least partially determined by the operation of the affect heuristic (De Martino et al., 2006), was amplified with increasing trait anxiety when making economic decisions. These findings support the viewpoint that emotion plays a crucial role in risk-based decision making (Loewenstein et al., 2001; Paulus and Yu, 2012). Considering the complexity of the underlying mechanisms of the framing effect, however, an alternative explanation of the current results exists. Because the framing effect may be generated from oversimplified processing of information to reduce cognitive demand (Gonzalez et al., 2005; Whitney et al., 2008), the behavioral findings might actually reflect the influence of anxiety on cognitive resources (Eysenck and Calvo, 1992) rather than on the sensitivity of emotional information. However, this explanation has difficulty accounting for activation of emotion-related brain regions, particularly the amygdala. Given that activation of both amygdala and dACC are altered with trait anxiety in the current study, a plausible account is that trait anxiety affects decision making by modulating both emotional and analytic systems (De Martino et al., 2006; Evans, 2008).

The dual-system model, proposed by Evans (2003, 2008), divides the process of decision making into contributions from two systems. The emotional system is fast, automatic, and influenced by emotional context, whereas the analytic system is slow, deliberative, and subject to the limits of working memory. De Martino et al. (2006) found that an "analytic" dACC-based neural system and an "emotional" amygdala-based neural system subserve frame-based decision making. Given that anxiety is associated with both heightened sensitivity to emotional information (Bishop et al., 2004) and impaired working memory (Eysenck et al., 2007; Basten et al., 2012), our findings provide support for the dual-system model of decision making in anxiety. Consistent with the aforementioned models, those with higher anxiety showed hyperactivation of the amygdala-based emotional system and hypoactivation of the dACC-based analytic system in our study.

The amygdala is generally related to the generation and experience of emotions (Aupperle and Paulus, 2010; Domschke and Dannlowski, 2010). It plays a pivotal role in emotional memory encoding and consolidation (Rasch et al., 2009; Groch et al., 2011). We speculate that, in decision-making tasks, the amygdala creates decision biases by promoting the recall of emotional 
Table 3. PPI of the amygdala ${ }^{a}$

\begin{tabular}{|c|c|c|c|c|c|c|c|c|c|}
\hline Region & $\mathrm{L} / \mathrm{R}$ & $B A$ & $x$ & $y$ & $z$ & $t$ & $Z$ & $p$ & $k$ \\
\hline \multicolumn{10}{|l|}{ Positive } \\
\hline Middle frontal gyrus & $\mathrm{L}$ & 9 & -32 & 42 & 32 & 5.34 & 4.13 & $<0.001$ & 42,415 \\
\hline Supplementary motor area & $\mathrm{R}$ & 6 & 10 & -26 & 54 & 5.01 & 3.95 & & \\
\hline Postcentral gyrus & $\mathrm{R}$ & 5 & 12 & -32 & 62 & 4.92 & 3.91 & & \\
\hline Postcentral gyrus & $\mathrm{L}$ & 3 & -56 & -18 & 46 & 4.69 & 3.78 & & \\
\hline Precentral gyrus & $\mathrm{L}$ & $4 / 6$ & -28 & -28 & 56 & 4.64 & 3.75 & & \\
\hline Supplementary motor area & $\mathrm{L}$ & 6 & -6 & -10 & 50 & 4.44 & 3.63 & & \\
\hline Anterior cingulate cortex (subgenual) & & 24 & 0 & 26 & -10 & 4.19 & 3.48 & & \\
\hline Postcentral & $\mathrm{R}$ & 3 & 24 & -32 & 58 & 3.93 & 3.32 & & \\
\hline Inferior frontal gyrus (opercular) & $\mathrm{R}$ & 44 & 50 & 16 & 8 & 3.93 & 3.32 & & \\
\hline Middle frontal gyrus & $\mathrm{L}$ & 10 & -34 & 50 & 8 & 3.89 & 3.29 & & \\
\hline \multicolumn{10}{|l|}{ Negative } \\
\hline Precuneus & $\mathrm{L}$ & 7 & -2 & -74 & 56 & 5.03 & 3.96 & $<0.001$ & 1743 \\
\hline Precuneus & $\mathrm{R}$ & 7 & 6 & -66 & 64 & 4.36 & 3.59 & & \\
\hline Inferior parietal lobule & $\mathrm{R}$ & 40 & 42 & -60 & 60 & 3.82 & 3.25 & & \\
\hline Lingual gyrus & L & 18 & -10 & -90 & -14 & 4.01 & 3.37 & $<0.001$ & 1603 \\
\hline Calcarine cortex & $\mathrm{L}$ & 17 & -8 & -98 & -6 & 2.89 & 2.6 & & \\
\hline Calcarine cortex & $\mathrm{R}$ & 18 & 2 & -84 & 14 & 2.73 & 2.48 & & \\
\hline Lingual gyrus & $\mathrm{R}$ & 19 & 22 & -72 & -10 & 2.37 & 2.19 & & \\
\hline
\end{tabular}

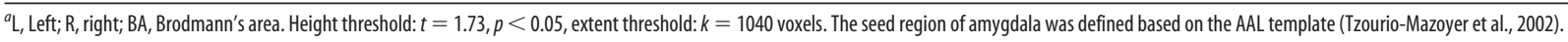

Table 4. Positive correlations between the PPI of the amygdala and trait anxiety ${ }^{a}$

\begin{tabular}{|c|c|c|c|c|c|c|c|c|c|}
\hline Region & $L / R$ & $B A$ & $x$ & $y$ & $Z$ & $t$ & $Z$ & $p$ & $k$ \\
\hline Anterior cingulate gyrus (pregenual) & $\mathrm{R}$ & $32 / 25$ & 12 & 38 & 16 & 4.96 & 3.89 & $<0.001$ & 32,843 \\
\hline Caudate & $L$ & & -8 & 16 & 14 & 4.06 & 3.38 & & \\
\hline Insula & $\mathrm{R}$ & & 36 & -8 & 22 & 4.01 & 3.35 & & \\
\hline Putamen & $L$ & & -26 & 16 & 2 & 4.05 & 3.37 & & \\
\hline Inferior temporal gyrus & $L$ & 20 & -42 & -34 & -12 & 4.7 & 3.75 & & \\
\hline Inferior temporal gyrus & $\mathrm{R}$ & 20 & 46 & -20 & -18 & 4.18 & 3.45 & & \\
\hline Thalamus & $\mathrm{L}$ & & -14 & -6 & 8 & 4.14 & 3.42 & & \\
\hline Cerebellum VI & $\mathrm{L}$ & & -12 & -70 & -22 & 3.71 & 3.16 & & \\
\hline Posterior cingulate gyrus & $L$ & 23 & -6 & -38 & 18 & 3.78 & 3.2 & & \\
\hline Middle frontal gyrus & $\mathrm{R}$ & 44 & 44 & 24 & 38 & 3.72 & 3.16 & & \\
\hline Middle frontal gyrus & $\mathrm{L}$ & 44 & -40 & 18 & 38 & 3.53 & 3.04 & & \\
\hline Fusiform & $L$ & 37 & -26 & -34 & -16 & 3.47 & 3 & & \\
\hline Insula & $L$ & & -28 & 32 & 10 & 3.71 & 3.16 & & \\
\hline Posterior cingulate gyrus & $\mathrm{R}$ & 31 & 12 & -58 & 40 & 3.88 & 3.26 & & \\
\hline Thalamus & $\mathrm{R}$ & & 14 & -6 & 2 & 3.87 & 3.26 & & \\
\hline Angular gyrus & $L$ & 39 & -44 & -52 & 34 & 3.37 & 2.93 & & \\
\hline Caudate & $\mathrm{R}$ & & 8 & 14 & 12 & 3.36 & 2.92 & & \\
\hline Superior frontal gyrus (medial) & L & 9 & -10 & 30 & 36 & 3.34 & 2.9 & & \\
\hline Putamen & $\mathrm{R}$ & & 26 & 18 & -6 & 3.28 & 2.87 & & \\
\hline Vermis VI & $\mathrm{R}$ & & 6 & -60 & -22 & 3.3 & 2.88 & & \\
\hline Cerebellum IV, V & $L$ & & -8 & -56 & -18 & 3.05 & 2.7 & & \\
\hline Superior frontal gyrus (orbital) & $\mathrm{L}$ & 11 & -22 & 46 & -10 & 3.16 & 2.78 & & \\
\hline Precuneus & $\mathrm{L}$ & 30 & -8 & -52 & 20 & 3.15 & 2.77 & & \\
\hline Cerebellum VI & $\mathrm{R}$ & & 18 & -74 & -22 & 2.96 & 2.64 & & \\
\hline Anterior cingulate gyrus (pregenual) & L & 32 & -12 & 46 & 8 & 3.02 & 2.68 & & \\
\hline Superior frontal gyrus (medial) & $\mathrm{R}$ & 10 & 14 & 56 & 20 & 3.03 & 2.69 & & \\
\hline Inferior frontal gyrus (orbital) & $L$ & 47 & -42 & 38 & -12 & 2.9 & 2.59 & & \\
\hline Cerebellum crus II & $\mathrm{R}$ & & 20 & -80 & -34 & 2.77 & 2.5 & & \\
\hline Inferior frontal gyrus (orbital) & $\mathrm{R}$ & 47 & 30 & 30 & -10 & 2.8 & 2.52 & & \\
\hline Angular gyrus & $L$ & 41 & -42 & -48 & 24 & 2.66 & 2.41 & & \\
\hline Cerebellum IX & $L$ & & -10 & -42 & -42 & 2.65 & 2.41 & & \\
\hline Hippocampus & $\mathrm{R}$ & & 38 & -12 & -14 & 2.59 & 2.36 & & \\
\hline
\end{tabular}

${ }^{a} \mathrm{~L}$, Left; $\mathrm{R}$, right; $\mathrm{BA}$, Brodmann's area. Height threshold: $t=1.73, p<0.05$, extent threshold: $k=1001$ voxels.

memories (Phelps, 2006) that are in the same valence category as the external emotional information (Bechara et al., 2000). Hence, emotionally positive and negative information lead to approach and avoidance behavior, respectively (Aupperle and Paulus, 2010). This idea explains why excessive amygdala activity could result in not only increased urges to avoid negative outcomes (De Martino et al., 2010) but also increased urges to obtain rewards
(Aupperle and Paulus, 2010). Considering risk-avoidance as securing a resource, along with risk-seeking as avoiding a resource loss (i.e., the reflection effect) (Kahneman and Frederick, 2007), our behavioral and neural findings also suggest that the amplified framing effect in anxious individuals during risk decision making may actually reflect heightened loss aversion rather than risk aversion (Hartley and Phelps, 2012). 
A

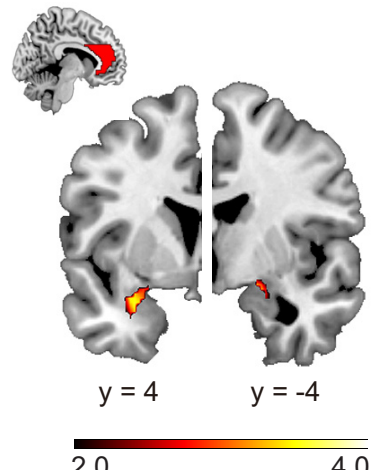

D

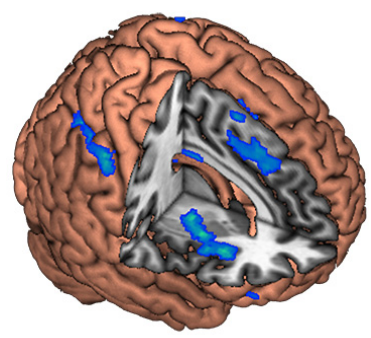

$-2.0$
B

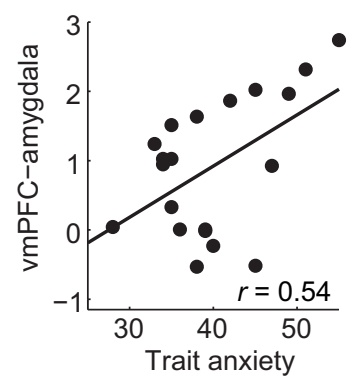

E

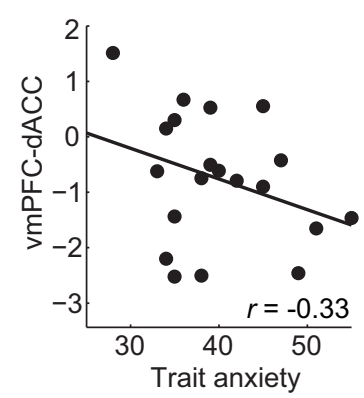

C

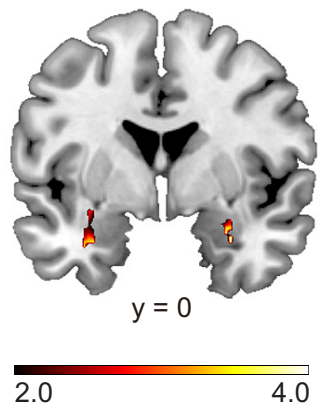

$\mathbf{F}$

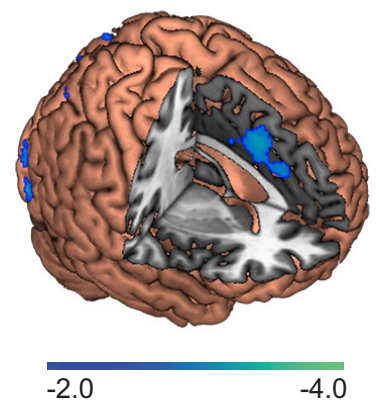

The findings that the modulation of the framing effect on neural circuits of amygdala-vmPFC and vmPFC-dACC, associated with trait anxiety, provide evidence that the vmPFC integrates information from these two systems to guide decisions (Schoenbaum et al., 2006). Previous studies have shown that the vmPFC is crucial for successful decision making (Bechara et al., 2000, 2004; Clark et al., 2008) and emotional value encoding (Winecoff et al., 2013). Some have proposed that the function of the vmPFC is to engage emotional feelings regarding current situations to guide the evaluation of different options in uncertain contexts (Naqvi et al., 2006). The vmPFC also plays an important role in top-down control of amygdala activity (Etkin et al., 2006). Disruptions of the amygdalavmPFC circuitry are centrally involved in the maintenance of anxiety symptoms (Kim and Whalen, 2009; Kim et al., 2011). Amygdala hyper-responsivity and prefrontal under-recruitment result in enhanced selective attention to threat as well as negative biases in threat interpretation, both of which characterize anxiety (Douglas et al., 1993; Bishop, 2007). Our results indicate that the amygdalavmPFC neural circuitry also influences decision-making preference (Rolls, 2006; Seymour and Dolan, 2008). The interactions between the vmPFC and dACC are also important for decision making (Blair et al., 2006). The connection of these two

The dACC is vital for inhibition function (Etkin et al., 2006) and is responsible for top-down control of amygdala activity (Ochsner and Gross, 2005). The relationship between anxiety and dACC activation is dynamic; both hyperactivation and hypoactivation of the dACC are linked to high levels of anxiety (Straube et al., 2009), indicating dysfunction of the inhibition mechanism (Huang et al., 2009; Ansari and Derakshan, 2011). Consistent with this idea, high-anxious people exhibit weaker inhibition of emotional stimuli (Derakshan et al., 2009) and excessive thought processes related to the inhibition of emotional experience (Borkovec et al., 1998). In this study, dampened dACC activity indicates that high-anxious individuals may struggle to suppress the activity of the amygdala-based system elicited by emotional framing.

In this study, we use the dual-system architecture to provide a simple scheme for interpreting our findings. However, this system and its focus on individual neural substrates are likely an oversimplification; the amygdala is clearly not the sole representative of the emotional system and the dACC is similarly likely not the sole representation of the analytic system. For example, the dACC plays a domain-general role in integrating negative affect and cognitive control (Shackman et al., 2011). More generally, the significance of the dual-system model is currently under debate (Seymour and Dolan, 2008; Quartz, 2009). However, the dual-system architecture does seem to provide a useful heuristic for understanding frame-dependent decision making (De Martino et al., 2006). regions is critical for fear extinction, emotional inhibition, and emotional regulation (Etkin et al., 2011). As a result of these separate network interactions with the vmPFC during decisionmaking processes, it is reasonable to speculate that the vmPFC functions as a "hub" that integrates the emotional inputs from the amygdala and regulatory signals from dACC. The result of this integration determines the subjective appraisal of each option for the individual. For the vmPFC, stronger connectivity with the amygdala and/or weaker connectivity with the dACC may lead to susceptibility to external emotional information. Thus, the framing effect would appear to be stronger in both of these cases. Furthermore, the pattern of altered vmPFC connectivity described above is more prominent with higher levels of trait anxiety.

The insula, which has also been associated with the framing effect (Deppe et al., 2005; Zheng et al., 2010), was negatively correlated with trait anxiety in the current study. The insula is critical for the representation of interoceptive information (Paulus and Stein, 2006; Gu et al., 2013). This area also affects risk estimations and reward predictions by modulating the interoceptive feelings associated with different options (Naqvi et al., 2006; Aupperle and Paulus, 2010). Increased interoceptive awareness among high-anxious individuals is mediated by altered insula reactivity (Hartley and Phelps, 2012). In this study, attenuated insula activation might result in high-anxious participants' bias to rely more strongly on external emotional cues rather than on interoceptive bodily sensations. Interestingly, previous studies 
Table 5. PPI of vmPFC ${ }^{a}$

\begin{tabular}{|c|c|c|c|c|c|c|c|c|c|}
\hline Region & $\mathrm{L} / \mathrm{R}$ & $\mathrm{BA}$ & $x$ & $y$ & $z$ & $T$ & Z & $p$ & $k$ \\
\hline \multicolumn{10}{|l|}{ Positive } \\
\hline Cerebellum crus I & $\mathrm{L}$ & & -42 & -58 & -28 & 5.04 & 3.97 & $<0.001$ & 6335 \\
\hline Superior frontal gyrus (medial) & L & 10 & -14 & 56 & 14 & 3.92 & 3.31 & & \\
\hline Anterior cingulate cortex (subgenual) & $\mathrm{L}$ & 32 & -4 & 44 & -4 & 3.76 & 3.21 & & \\
\hline Superior frontal gyrus (medial) & R & 10 & 6 & 58 & 22 & 3.47 & 3.02 & & \\
\hline Hippocampus & L & & -24 & -20 & -10 & 3.33 & 2.92 & & \\
\hline Cerebellum VI & L & & -20 & -62 & -14 & 3.14 & 2.78 & & \\
\hline Inferior frontal gyrus (orbital) & L & 47 & -34 & 26 & -14 & 3.13 & 2.78 & & \\
\hline Caudate & L & & -16 & 22 & -2 & 3 & 2.68 & & \\
\hline Temporal pole (middle temporal gyrus) & $\mathrm{L}$ & 20 & -42 & 10 & -32 & 2.92 & 2.62 & & \\
\hline Anterior cingulate cortex (pregenual) & $\mathrm{R}$ & 24 & 2 & 34 & 10 & 2.91 & 2.61 & & \\
\hline Angular & $\mathrm{L}$ & 39 & -42 & -70 & 32 & 2.82 & 2.54 & & \\
\hline Posterior cingulate cortex & R & $30 / 23$ & 4 & -48 & 18 & 2.74 & 2.49 & & \\
\hline Amygdala $^{b}$ & $\mathrm{~L}$ & & -30 & 6 & 18 & 3.58 & 3.09 & $<0.001$ & 98 \\
\hline Amygdala $^{b}$ & R & & 22 & -6 & -14 & 3.34 & 2.93 & $<0.005$ & 49 \\
\hline \multicolumn{10}{|l|}{ Negative } \\
\hline Inferior parietal lobule & R & 40 & 32 & -52 & 38 & 5.01 & 3.95 & $<0.001$ & 3675 \\
\hline Superior parietal lobule & R & 7 & 26 & -64 & 44 & 3.38 & 2.95 & & \\
\hline Middle occipital gyrus & R & 7 & 34 & -76 & 42 & 3.06 & 2.73 & & \\
\hline Supramarginal gyrus & $\mathrm{R}$ & 40 & 46 & -48 & 28 & 3 & 2.68 & & \\
\hline Superior temporal gyrus & R & 41 & 54 & -40 & 16 & 2.92 & 2.62 & & \\
\hline Precuneus & $\mathrm{R}$ & 7 & 12 & -74 & 48 & 2.82 & 2.54 & & \\
\hline Cerebellum VI & $\mathrm{L}$ & & -22 & -68 & -26 & 4.89 & 3.89 & $<0.001$ & 985 \\
\hline Cerebellum crus II & L & & -8 & -80 & -30 & 3.73 & 3.19 & & \\
\hline Insula & $\mathrm{R}$ & & 36 & 24 & 2 & 3.64 & 3.13 & & \\
\hline Pallidum & $\mathrm{R}$ & & 22 & -2 & 2 & 3.61 & 3.11 & & \\
\hline Inferior frontal gyrus (opercular) & $\mathrm{R}$ & 44 & 44 & 16 & 14 & 3.55 & 3.07 & & \\
\hline Thalamus & L & & -12 & -22 & 18 & 3.26 & 2.87 & & \\
\hline Anterior cingulate cortex (dorsal) & R & 32 & 10 & 20 & 42 & 3.23 & 2.85 & & \\
\hline Superior frontal gyrus (medial) & $\mathrm{R}$ & 8 & 6 & 26 & 46 & 3.07 & 2.73 & & \\
\hline Anterior cingulate cortex (dorsal) & L & 33 & -2 & 4 & 30 & 3 & 2.68 & & \\
\hline Precentral & L & 6 & -38 & 0 & 52 & 4.1 & 3.43 & $<0.001$ & 3090 \\
\hline Inferior frontal gyrus & L & 46 & -36 & 28 & 18 & 3.55 & 3.07 & & \\
\hline Middle frontal gyrus & $\mathrm{L}$ & 46 & -42 & 12 & 34 & 3.45 & 3 & & \\
\hline Middle frontal gyrus & $\mathrm{L}$ & 10 & -42 & 56 & 4 & 3.09 & 2.74 & & \\
\hline Putamen & L & & -24 & 2 & 8 & 3.08 & 2.74 & & \\
\hline Insula & $\mathrm{L}$ & & -28 & 22 & 8 & 2.45 & 2.25 & & \\
\hline Middle frontal gyrus (orbital) & $\mathrm{L}$ & 10 & -38 & 50 & 0 & 2.43 & 2.24 & & \\
\hline Pallidum & L & & -24 & -6 & -4 & 2.37 & 2.19 & & \\
\hline Inferior parietal lobule & $\mathrm{L}$ & 40 & -50 & -36 & 44 & 4.01 & 3.37 & $<0.001$ & 3007 \\
\hline Superior parietal lobule & $\mathrm{L}$ & 7 & -22 & -66 & 36 & 3.56 & 3.08 & & \\
\hline
\end{tabular}

${ }^{a} \mathrm{~L}, \mathrm{Left} ; \mathrm{R}$, right; $\mathrm{BA}$, Brodmann's area. Height threshold: $t=1.73, p<0.05$, extent threshold: $k=840$ voxels. The seed region of vmPFC was defined based on the AAL template (Tzourio-Mazoyer et al., 2002).

${ }^{b}$ For the amygdala, a small-volume correction (Worsley et al., 1996) was applied, with an anatomical mask derived from the AAL atlas (Tzourio-Mazoyer et al., 2002) and with a voxel-level threshold $p_{\text {uncorrected }}<0.05$ and a search volume of $2200 \mathrm{~mm}^{3}$ (275 voxels).

suggest that the insula affects emotional decision making via its extensive reciprocal connectivity with the vmPFC (Augustine, 1996; Ongür and Price, 2000; Clark et al., 2008). Similar to the amygdala and the dACC, the association between the insular activity and frame-dependent decision making in anxiety might also be mediated by the vmPFC, but further research is needed to examine this hypothesis.

Whereas most studies on risk-based decision making in anxiety have shown that anxiety is associated with risk-avoidance or, less often, risk-seeking, our findings suggest that the impact of 
Table 6. Correlations between PPI of vmPFC and trait anxiety ${ }^{a}$

\begin{tabular}{|c|c|c|c|c|c|c|c|c|c|}
\hline Region & $\mathrm{L} / \mathrm{R}$ & BA & $x$ & $y$ & $z$ & $T$ & $Z$ & $p$ & $k$ \\
\hline \multicolumn{10}{|l|}{ Positive } \\
\hline Middle temporal gyrus & $\mathrm{L}$ & 21 & -46 & -12 & -12 & 5.89 & 4.34 & $<0.001$ & 21,012 \\
\hline Middle temporal pole & L & 38 & -40 & 10 & -26 & 5.24 & 4.03 & & \\
\hline Inferior temporal gyrus & $\mathrm{R}$ & 20 & 44 & -14 & -24 & 5.05 & 3.94 & & \\
\hline Postcentral & $\mathrm{R}$ & 3 & 38 & -28 & 38 & 5.01 & 3.91 & & \\
\hline Putamen & $\mathrm{R}$ & & 28 & 14 & -6 & 4.69 & 3.74 & & \\
\hline Insula & $\mathrm{R}$ & & 28 & 16 & -18 & 4.31 & 3.52 & & \\
\hline Posterior cingulate gyrus & $\mathrm{R}$ & 23 & 10 & -38 & 16 & 4.21 & 3.46 & & \\
\hline Posterior cingulate gyrus & L & 23 & -6 & -38 & 16 & 4.19 & 3.46 & & \\
\hline Inferior frontal gyrus (triangular) & L & 45 & -46 & 32 & 6 & 4.01 & 3.34 & & \\
\hline Inferior frontal gyrus (orbital) & $\mathrm{L}$ & 47 & -26 & 26 & -14 & 3.92 & 3.29 & & \\
\hline Hippocampus & $\mathrm{L}$ & & -30 & -2 & -26 & 3.91 & 3.29 & & \\
\hline Middle temporal pole & $\mathrm{R}$ & 38 & 40 & 16 & -32 & 3.52 & 3.03 & & \\
\hline Precentral & L & 6 & -32 & 2 & 48 & 3.42 & 2.96 & & \\
\hline Supplemental motor area & $\mathrm{R}$ & 6 & 12 & -12 & 64 & 3.42 & 2.96 & & \\
\hline Cerebellum IV, V & $\mathrm{R}$ & & 10 & -48 & -4 & 3.41 & 2.95 & & \\
\hline Superior occipital gyrus & L & 19 & -22 & -64 & 30 & 3.38 & 2.94 & & \\
\hline Precuneus & $\mathrm{L}$ & 29 & -12 & -44 & 14 & 3.26 & 2.85 & & \\
\hline Middle temporal gyrus & $\mathrm{R}$ & 21 & 60 & -8 & -16 & 3.2 & 2.81 & & \\
\hline Cerebellum VI & $\mathrm{R}$ & & 16 & -58 & -14 & 3.16 & 2.78 & & \\
\hline Cerebellum VI & L & & -24 & -52 & -28 & 3.08 & 2.72 & & \\
\hline Angular & $\mathrm{R}$ & 39 & 42 & -50 & 26 & 3.05 & 2.7 & & \\
\hline Lingual gyrus & $\mathrm{L}$ & 18 & -14 & -46 & 2 & 3 & 2.67 & & \\
\hline Postcentral & $\mathrm{L}$ & 3 & -16 & -34 & 72 & 2.98 & 2.65 & & \\
\hline Superior frontal gyrus & $\mathrm{R}$ & 10 & 20 & 54 & 8 & 4.11 & 3.41 & & \\
\hline Anterior cingulate gyrus (pregenual) & $\mathrm{R}$ & 24 & 12 & 36 & 6 & 3.52 & 3.03 & & \\
\hline Anterior cingulate gyrus (pregenual) & $\mathrm{L}$ & 24 & -8 & 42 & 10 & 3.42 & 2.96 & & \\
\hline Amygdala $^{b}$ & $\mathrm{R}$ & & 30 & 0 & -24 & 4.49 & 3.63 & $<0.001$ & 37 \\
\hline Amygdala $^{b}$ & L & & -30 & -2 & -26 & 3.91 & 3.29 & $<0.001$ & 81 \\
\hline \multicolumn{10}{|l|}{ Negative } \\
\hline Calcarine cortex & $\mathrm{L}$ & 17 & -10 & -102 & 0 & 6.15 & 4.46 & $<0.001$ & 8726 \\
\hline Inferior occipital gyrus & L & 18 & -14 & -98 & -8 & 5.24 & 4.03 & & \\
\hline Cuneus & $\mathrm{R}$ & 17 & 14 & -96 & 10 & 5.11 & 3.96 & & \\
\hline Lingual gyrus & L & 18 & -14 & -90 & -10 & 4.91 & 3.86 & & \\
\hline Lingual gyrus & $\mathrm{R}$ & 18 & 24 & -92 & -8 & 4.57 & 3.67 & & \\
\hline Precuneus & $\mathrm{R}$ & 7 & 10 & -72 & 46 & 4.55 & 3.66 & & \\
\hline Inferior occipital gyrus & R & 19 & 44 & -84 & -4 & 4.11 & 3.41 & & \\
\hline Superior occipital gyrus & L & 7 & -12 & -76 & 44 & 3.94 & 3.3 & & \\
\hline Middle occipital gyrus & L & 18 & -42 & -90 & 2 & 3.78 & 3.2 & & \\
\hline Middle occipital gyrus & $\mathrm{R}$ & 18 & 34 & -92 & 12 & 3.77 & 3.19 & & \\
\hline Cuneus & L & 19 & -4 & -88 & 38 & 3.74 & 3.18 & & \\
\hline Fusiform & L & 19 & -44 & -64 & -16 & 3.71 & 3.15 & & \\
\hline Cerebellum crus I & $\mathrm{L}$ & & -44 & -62 & -28 & 3.62 & 3.09 & & \\
\hline Calcarine cortex & $\mathrm{R}$ & 17 & 14 & -82 & 4 & 3.52 & 3.03 & & \\
\hline Fusiform & $\mathrm{R}$ & 19 & 30 & -68 & -14 & 3.08 & 2.72 & & \\
\hline Superior occipital gyrus & $\mathrm{R}$ & 7 & 30 & -68 & 58 & 2.77 & 2.49 & & \\
\hline Middle cingulate gyrus (dorsal) & R & 24 & 4 & 18 & 32 & 4.02 & 3.35 & $<0.001$ & 917 \\
\hline Middle cingulate gyrus (dorsal) & $\mathrm{L}$ & $32 / 24$ & -4 & 18 & 40 & 3.94 & 3.3 & & \\
\hline
\end{tabular}

${ }^{a} \mathrm{~L}$, Left; $\mathrm{R}$, right; BA, Brodmann's area. Height threshold: $t=1.73, p<0.05$, extent threshold: $k=818$ voxels.

${ }^{b}$ For the amygdala, a small-volume correction (Worsley et al., 1996) was applied, with an anatomical mask derived from the AAL atlas (Tzourio-Mazoyer et al., 2002) and with a voxel-level threshold $p_{\text {uncorrected }}<0.05$ and a search volume of $2200 \mathrm{~mm}^{3}$ (275 voxels). 
anxiety on risk-based decision making actually reflects an anxiety-based vulnerability to emotional information, which is underpinned by the hyper-responsivity of "emotional" neural systems and under-recruitment of "analytic" neural systems.

\section{References}

Ansari TL, Derakshan N (2011) The neural correlates of impaired inhibitory control in anxiety. Neuropsychologia 49:1146-1153. CrossRef Medline

Augustine JR (1996) Circuitry and functional aspects of the insular lobe in primates including humans. Brain Res Brain Res Rev 22:229-244. CrossRef Medline

Aupperle RL, Paulus MP (2010) Neural systems underlying approach and avoidance in anxiety disorders. Dialogues Clin Neurosci 12:517-531. Medline

Bar-Haim Y, Lamy D, Pergamin L, Bakermans-Kranenburg MJ, van IJzendoorn MH (2007) Threat-related attentional bias in anxious and nonanxious individuals: a meta-analytic study. Psychol Bull 133:1-24. CrossRef Medline

Basten U, Stelzel C, Fiebach CJ (2012) Trait anxiety and the neural efficiency of manipulation in working memory. Cogn Affect Behav Neurosci 12: 571-588. CrossRef Medline

Bechara A (2004) The role of emotion in decision-making: evidence from neurological patients with orbitofrontal damage. Brain Cogn 55:30-40. CrossRef Medline

Bechara A, Damasio H, Damasio AR (2000) Emotion, decision making and the orbitofrontal cortex. Cereb Cortex 10:295-307. CrossRef Medline

Bishop SJ (2007) Neurocognitive mechanisms of anxiety: an integrative account. Trends Cogn Sci 11:307-316. CrossRef Medline

Bishop S, Duncan J, Brett M, Lawrence AD (2004) Prefrontal cortical function and anxiety: controlling attention to threat-related stimuli. Nat Neurosci 7:184-188. CrossRef Medline

Blair K, Marsh AA, Morton J, Vythilingam M, Jones M, Mondillo K, Pine DC, Drevets WC, Blair JR (2006) Choosing the lesser of two evils, the better of two goods: specifying the roles of ventromedial prefrontal cortex and dorsal anterior cingulate in object choice. J Neurosci 26:11379-11386. CrossRef Medline

Borkovec TD, Ray WJ, Stober J (1998) Worry: a cognitive phenomenon intimately linked to affective, physiological, and interpersonal behavioral processes. Cogn Ther Res 22:561-576. CrossRef

Chapman J (2006) Anxiety and defective decision making: an elaboration of the groupthink model. Manage Decis 44:1391-1404. CrossRef

Clark DM (1999) Anxiety disorders: why they persist and how to treat them. Behav Res Ther 37:S5-S27. CrossRef Medline

Clark LA, Watson D (1991) Tripartite model of anxiety and depression: psychometric evidence and taxonomic implications. J Abnorm Psychol 100:316-336. CrossRef Medline

Clark L, Bechara A, Damasio H, Aitken MR, Sahakian BJ, Robbins TW (2008) Differential effects of insular and ventromedial prefrontal cortex lesions on risky decision-making. Brain 131:1311-1322. CrossRef Medline

Deisseroth K, Tye KM, Prakash R, Kim SY, Fenno LE, Grosenick L, Zarabi H, Thompson KR, Gradinaru V, Ramakrishnan C (2011) Amygdala circuitry mediating reversible and bidirectional control of anxiety. Nature 471:358-362. CrossRef Medline

De Martino B, Kumaran D, Seymour B, Dolan RJ (2006) Frames, biases, and rational decision-making in the human brain. Science 313:684-687. CrossRef Medline

De Martino B, Camerer CF, Adolphs R (2010) Amygdala damage eliminates monetary loss aversion. Proc Natl Acad Sci U S A 107:3788-3792. CrossRef Medline

Deppe M, Schwindt W, Krämer J, Kugel H, Plassmann H, Kenning P, Ringelstein EB (2005) Evidence for a neural correlate of a framing effect: biasspecific activity in the ventromedial prefrontal cortex during credibility judgments. Brain Res Bull 67:413-421. CrossRef Medline

Deppe M, Schwindt W, Pieper A, Kugel H, Plassmann H, Kenning P, Deppe K, Ringelstein EB (2007) Anterior cingulate reflects susceptibility to framing during attractiveness evaluation. Neuroreport 18:1119-1123. CrossRef Medline

Derakshan N, Ansari TL, Hansard M, Shoker L, Eysenck MW (2009) Anxiety, inhibition, efficiency, and effectiveness: an investigation using the antisaccade task. Exp Psychol 56:48-55. CrossRef Medline

de Visser L, van der Knaap LJ, van de Loo AJ, van der Weerd CM, Ohl F, van den Bos R (2010) Trait anxiety affects decision-making differently in healthy men and women: towards gender-specific endophenotypes of anxiety. Neuropsychologia 48:1598-1606. CrossRef Medline

Domschke K, Dannlowski U (2010) Imaging genetics of anxiety disorders. Neuroimage 53:822-831. CrossRef Medline

Douglas JF, Johnson HE, Granick S (1993) A simple kinetic model of polymer adsorption and desorption. Science 262:2010-2012. CrossRef Medline

Druckman JN, McDermott R (2008) Emotion and the framing of risky choice. Polit Behav 30:297-321. CrossRef

Etkin A, Egner T, Peraza DM, Kandel ER, Hirsch J (2006) Resolving emotional conflict: a role for the rostral anterior cingulate cortex in modulating activity in the amygdala. Neuron 51:871-882. CrossRef Medline

Etkin A, Egner T, Kalisch R (2011) Emotional processing in anterior cingulate and medial prefrontal cortex. Trends Cogn Sci 15:85-93. CrossRef Medline

Evans JS (2003) In two minds: dual-process accounts of reasoning. Trends Cogn Sci 7:454-459. CrossRef Medline

Evans JS (2008) Dual-processing accounts of reasoning, judgment, and social cognition. Annu Rev Psychol 59:255-278. CrossRef Medline

Eysenck MW, Calvo MG (1992) Anxiety and performance: the processing efficiency theory. Cogn Emotion 6:409-434. CrossRef

Eysenck MW, Derakshan N, Santos R, Calvo MG (2007) Anxiety and cognitive performance: attentional control theory. Emotion 7:336-353. CrossRef Medline

Fagley NS, Coleman JG, Simon AF (2010) Effects of framing, perspective taking, and perspective (affective focus) on choice. Pers Indiv Differ 48: 264-269. CrossRef

Finucane ML, Alhakami A, Slovic P, Johnson SM (2000) The affect heuristic in judgments of risks and benefits. J Behav Decis Making 13:1-17. CrossRef

Forman SD, Cohen JD, Fitzgerald M, Eddy WF, Mintun MA, Noll DC (1995) Improved assessment of significant activation in functional magnetic resonance imaging (fMRI): use of a cluster-size threshold. Magn Reson Med 33:636-647. CrossRef Medline

Friston KJ, Worsley KJ, Frackowiak RSJ, Mazziotta JC, Evans AC (1994) Assessing the significance of focal activations using their spatial extent. Hum Brain Mapp 1:210-220.

Friston KJ, Frith CD, Turner R, Frackowiak RS (1995) Characterizing evoked hemodynamics with fMRI. Neuroimage 2:157-165. CrossRef Medline

Gonzalez C, Dana J, Koshino H, Just M (2005) The framing effect and risky decisions: Examining cognitive functions with fMRI. J Econ Psychol 26: 1-20. CrossRef

Griswold MA, Jakob PM, Heidemann RM, Nittka M, Jellus V, Wang J, Kiefer B, Haase A (2002) Generalized autocalibrating partially parallel acquisitions (GRAPPA). Magn Reson Med 47:1202-1210. CrossRef Medline

Groch S, Wilhelm I, Diekelmann S, Sayk F, Gais S, Born J (2011) Contribution of norepinephrine to emotional memory consolidation during sleep. Psychoneuroendocrinology 36:1342-1350. CrossRef Medline

Gu R, Ge Y, Jiang Y, Luo YJ (2010a) Anxiety and outcome evaluation: the good, the bad and the ambiguous. Biol Psychol 35:200-206. CrossRef Medline

Gu R, Huang YX, Luo YJ (2010b) Anxiety and feedback negativity. Psychophysiology 47:961-967. CrossRef Medline

Gu X, Hof PR, Friston KJ, Fan J (2013) Anterior insular cortex and emotional awareness. J Comp Neurol 521:3371-3388. CrossRef Medline

Hampton AN, Adolphs R, Tyszka MJ, O’Doherty JP (2007) Contributions of the amygdala to reward expectancy and choice signals in human prefrontal cortex. Neuron 55:545-555. CrossRef Medline

Hartley CA, Phelps EA (2012) Anxiety and decision-making. Biol Psychiatry 72:113-118. CrossRef Medline

Huang YX, Bai L, Ai H, Li W, Yu C, Liu J, Luo YJ (2009) Influence of trait-anxiety on inhibition function: evidence from ERPs study. Neurosci Lett 456:1-5. CrossRef Medline

Indovina I, Robbins TW, Núñez-Elizalde AO, Dunn BD, Bishop SJ (2011) Fear-conditioning mechanisms associated with trait vulnerability to anxiety in humans. Neuron 69:563-571. CrossRef Medline

Kahneman D, Frederick S (2007) Frames and brains: elicitation and control of response tendencies. Trends Cogn Sci 11:45-46. CrossRef Medline

Kim MJ, Whalen PJ (2009) The structural integrity of an amygdala- 
prefrontal pathway predicts trait anxiety. J Neurosci 29:11614-11618. CrossRef Medline

Kim MJ, Gee DG, Loucks RA, Davis FC, Whalen PJ (2011) Anxiety dissociates dorsal and ventral medial prefrontal cortex functional connectivity with the amygdala at rest. Cereb Cortex 21:1667-1673. CrossRef Medline

Kühberger A, Schulte-Mecklenbeck M, Perner J (1999) The effects of framing, reflection, probability, and payoff on risk preference in choice tasks. Organ Behav Hum Decis Process 78:204-231. CrossRef Medline

Loewenstein GF, Weber EU, Hsee CK, Welch N (2001) Risk as feelings. Psychol Bull 127:267-286. CrossRef Medline

Maner JK, Schmidt NB (2006) The role of risk avoidance in anxiety. Behav Ther 37:181-189. CrossRef Medline

Mathews A, Mogg K, May J, Eysenck M (1989) Implicit and explicit memory bias in anxiety. J Abnorm Psychol 98:236-240. CrossRef Medline

Mittal VV, Ross WT (1998) The impact of positive and negative affect and issue framing on issue interpretation and risk taking. Organ Behav Hum Decis Process 76:298-324. CrossRef Medline

Mitte K (2007) Anxiety and risk decision-making: the role of subjective probability and subjective cost of negative events. Pers Individual Differences 43:243-253. CrossRef

Mowinckel AM, Espeseth T, Westlye LT (2012) Network-specific effects of age and in-scanner subject motion: a resting-state fMRI study of 238 healthy adults. Neuroimage 63:1364-1373. CrossRef Medline

Naqvi N, Shiv B, Bechara A (2006) The role of emotion in decision making: a cognitive neuroscience perspective. Curr Dir Psychol Sci 15:260-264. CrossRef

Nesse RM (2006) Darwinian medicine and mental disorders. Intl Congress Series 1296:83-94. CrossRef

Nitschke JB, Sarinopoulos I, Oathes DJ, Johnstone T, Whalen PJ, Davidson RJ, Kalin NH (2009) Anticipatory activation in the amygdala and anterior cingulate in generalized anxiety disorder and prediction of treatment response. Am J Psychiatry 166:302-310. CrossRef Medline

Ochsner KN, Gross JJ (2005) The cognitive control of emotion. Trends Cogn Sci 9:242-249. CrossRef Medline

Ongür D, Price JL (2000) The organization of networks within the orbital and medial prefrontal cortex of rats, monkeys and humans. Cereb Cortex 10:206-219. CrossRef Medline

Paulus MP, Stein MB (2006) An insular view of anxiety. Biol Psychiatry 60:383-387. CrossRef Medline

Paulus MP, Yu AJ (2012) Emotion and decision-making: affect-driven belief systems in anxiety and depression. Trends Cogn Sci 16:476-483. CrossRef Medline

Phelps EA (2006) Emotion and cognition: insights from studies of the human amygdala. Annu Rev Psychol 57:27-53. CrossRef Medline

Power JD, Barnes KA, Snyder AZ, Schlaggar BL, Petersen SE (2012) Spurious but systematic correlations in functional connectivity MRI networks arise from subject motion. Neuroimage 59:2142-2154. CrossRef Medline

Quartz SR (2009) Reason, emotion and decision-making: risk and reward computation with feeling. Trends Cogn Sci 13:209-215. CrossRef Medline

Rasch B, Spalek K, Buholzer S, Luechinger R, Boesiger P, Papassotiropoulos A, de Quervain DJ (2009) A genetic variation of the noradrenergic system is related to differential amygdala activation during encoding of emotional memories. Proc Natl Acad Sci U S A 106:19191-19196. CrossRef Medline

Roiser JP, de Martino B, Tan GC, Kumaran D, Seymour B, Wood NW, Dolan RJ (2009) A genetically mediated bias in decision making driven by failure of amygdala control. J Neurosci 29:5985-5991. CrossRef Medline

Rolls ET (2006) Brain mechanisms of emotion and decision-making. Intl Congress Series 1291:3-13. CrossRef
Satterthwaite TD, Wolf DH, Loughead J, Ruparel K, Elliott MA, Hakonarson H, Gur RC, Gur RE (2012) Impact of in-scanner head motion on multiple measures of functional connectivity: relevance for studies of neurodevelopment in youth. Neuroimage 60:623-632. CrossRef Medline

Schoenbaum G, Roesch MR, Stalnaker TA (2006) Orbitofrontal cortex, decision-making and drug addiction. Trends Neurosci 29:116-124. CrossRef Medline

Seymour B, Dolan R (2008) Emotion, decision making, and the amygdala. Neuron 58:662-671. CrossRef Medline

Shackman AJ, Salomons TV, Slagter HA, Fox AS, Winter JJ, Davidson RJ (2011) The integration of negative affect, pain and cognitive control in the cingulate cortex. Nat Rev Neurosci 12:154-167. CrossRef Medline

Shek DT (1993) The Chinese version of the State-Trait Anxiety Inventory: its relationship to different measures of psychological well-being. J Clin Psychol 49:349-358. CrossRef Medline

Shu L (1993) Self-rating depression scale and depression status inventory. Chin J Mental Health 7 [Suppl]:160-162.

Slovic P, Finucane ML, Peters E, MacGregor DG (2004) Risk as analysis and risk as feelings: some thoughts about affect, reason, risk, and rationality. Risk Analysis 24:311-322. CrossRef Medline

Slovic P, Peters E, Finucane ML, MacGregor DG (2005) Affect, risk, and decision making. Health Psychol 24:S35-S40. CrossRef Medline

Spielberger CD, Gorsuch RL, Lushene R, Vagg PR, Jacobs GA (1983) Manual for the state-trait anxiety inventory. Palo Alto, CA: Consulting Psychologist.

Stavrakaki C, Vargo B (1986) The relationship of anxiety and depression: a review of the literature. Br J Psychiatry 149:7-16. CrossRef Medline

Straube T, Schmidt S, Weiss T, Mentzel HJ, Miltner WH (2009) Dynamic activation of the anterior cingulate cortex during anticipatory anxiety. Neuroimage 44:975-981. CrossRef Medline

Tang GS, van den Bos W, Andrade EB, McClure SM (2012) Social anxiety modulates risk sensitivity through activity in the anterior insula. Front Neurosci 5:142. CrossRef Medline

Tversky A, Kahneman D (1981) The framing of decisions and the psychology of choice. Science 211:453-458. CrossRef Medline

Tzourio-Mazoyer N, Landeau B, Papathanassiou D, Crivello F, Etard O, Delcroix N, Mazoyer B, Joliot M (2002) Automated anatomical labeling of activations in SPM using a macroscopic anatomical parcellation of the MNI MRI single-subject brain. Neuroimage 15:273-289. CrossRef Medline

Van Dijk KR, Sabuncu MR, Buckner RL (2012) The influence of head motion on intrinsic functional connectivity MRI. Neuroimage 59:431-438. CrossRef Medline

Whitney P, Rinehart CA, Hinson JM (2008) Framing effects under cognitive load: The role of working memory in risky decisions. Psychon Bull Rev 15:1179-1184. Medline

Winecoff A, Clithero JA, Carter RM, Bergman SR, Wang L, Huettel SA (2013) Ventromedial prefrontal cortex encodes emotional value. J Neurosci 33:11032-11039. CrossRef Medline

Worsley KJ, Evans AC, Marrett S, Neelin P (1992) A three-dimensional statistical analysis for $\mathrm{CBF}$ activation studies in human brain. J Cereb Blood Flow Metab 12:900-918. CrossRef Medline

Worsley KJ, Marrett S, Neelin P, Vandal AC, Friston KJ, Evans AC (1996) A unified statistical approach for determining significant signals in images of cerebral activation. Hum Brain Mapp 4:58-73. CrossRef Medline

Zheng H, Wang XT, Zhu L (2010) Framing effects: behavioral dynamics and neural basis. Neuropsychologia 48:3198-3204. CrossRef Medline

Zung WW, Richards CB, Short MJ (1965) Self-rating depression scale in an outpatient clinic: further validation of the SDS. Arch Gen Psychiatry 13: 508-515. CrossRef Medline 